\title{
THE EARLY INTERVENTION TENDENCY OF CHINESE CHILDREN WITH COCHLEAR IMPLANTS
}

\author{
Jiaojiao Wu, Yuhan Xie \\ Faculty of Education, Palacký University, Olomouc, Czech Republic \\ Sichuan Normal University, China
}

\begin{abstract}
From the change of adult unilateral cochlear implantation into young children even under the age of six implant cochlear, sequential bilateral cochlear implantation, which benefit by early hearing screening and technological development of cochlear implants. It is a worldwide trend that simultaneous bilateral cochlear implantation for hearing impaired children under the age of three. Cochlear implants bring changes of education opportunities and choices for children with hearing impairment. Family-centered postoperative early intervention is important, at the same time, hearing impaired children group characteristics tend to be diversified. A growing number of children with cochlear implants study in regular school, consequently, the number of deaf student is decreasing in deaf school. Regular school faces the challenge of lacking of professional teaching staff.
\end{abstract}

Keywords: cochlear implants, early intervention, family-centered, school.

\section{Introduction}

China is a country with huge population with hearing impairment, since Chinese domestic cochlear implants came into the market, more and more children accept cochlear implants surgery in earlier ages than before. To focus on the assessment and monitoring of hearing, speech and language, cognitive and social emotional development is required to meet a real need. Especially, early intervention team building and cooperation of multidisciplinary are really important. Family-centered early intervention plays an irreplaceable important role, meanwhile, parents are faced with a series of problems to be solved listed as group characteristics of children with cochlear implants tend towards diversification. To demonstrate early intervention tendency of children with cochlear implants, though literature review the author summarize three main tendencies of early intervention.

\section{The text of the paper}

With unceasing development of modern science and technology, life of the deaf is hugely impacted by hearing compensation device. Cochlear implant is the most obviously one, which is intended for completely deaf individuals and 
individuals with the practically non-utilizable remainder of the hearing. In 2011, Chinese domestic cochlear implants came into the market, which break monopoly situation of three companies, namely, the Australia Cochlear, the United States Advanced Bionics and Austrian MED-EL. Soon the first domestic cochlear implant surgery was successfully completed. It is noteworthy that the price is only half or even one third of the imported cochlear implants. Another data which we should pay attention to, the number of population with hearing impairment reaches 27.8 million in the mainland of China. And about 578000 children (0-17 years old), about 137000 children aged from 0 to 6 years old), 74 $\%$ of them with moderate or severe hearing impairment (Liu \& Sun, 2012). Such set of data means that hypothesis of more children choose cochlear implants. Since appearance of cochlear implants, several huge changes exit: first of all, parents of children with hearing impairment no longer struggle with whether implant cochlear, in generally, most of them choose cochlear implants as early as possible once after hearing screening diagnosis; the second, the popularity of newborn hearing screening, which support the implement of early intervention; the third, deaf education achievement (Liu, 2009) is more focused than before, multidisciplinary collaboration related areas such as cognitive psychology, neuroscience, linguistics and other disciplines, which support comprehensive understanding of learning process of those children with cochlear implants. Last but not the least, children with cochlear implants and their parents have more consciousness of rights to choose mainstream education. Actually, some studies (Wu, 2014) indicate that the main purpose for them to choose cochlear implants is promoting listening and oral communication. In generally, parents hold highly education expectation, although phenomena of some children with cochlear implants moved from regular school to deaf school were found, however, on the whole, parents tend to regular school educational placement.

According to the age, children with cochlear implants include different three age levels: older children with cochlear implants who are studying in middle or high school; children with early cochlear implants before 6 years old, now they are studying in elementary school; experienced early hearing screening diagnosis, preschool children who had cochlear implants before 2 years old. Era of unilateral cochlear implant could become a thing of the past. Recent years, increasing number of bilateral cochlear implants happens in the worldwide, which has becoming an international trend. Robert Peters and colleagues (Peters et al., 2010) investigated a total of 35 well-known large scale (cochlear implants number>250) cochlear implants in the range of Canada, the United States, Europe and Australia, which found that a number of 23200 users from all over the world, bilateral cochlear implant accounted for $36 \%$, and the proportion will be greatly increased. $70 \%$ of them are children, and $33 \%$ of children aged 3 to 10 years old, $30 \%$ of adult, children younger than 3 years old accounted for 
$26 \%$, and $11 \%$ children aged 11 to 18 years old. The number of children younger than 3 years old with bilateral cochlear implants is increasing obviously, more and more children simultaneously implant bilaterally instead of successively implantation. Advantages of bilateral cochlear implants are obvious, which improve the ability of sound positioning and speech discrimination in noise environment (Sparreboom et al., 2010). Especially, in regular school, large class size even reaches 45 students. Children are often studying in a noisy classroom, or working in a large group. Sound position and speech recognition should not be ignored. Bilateral cochlear implants give promotion of auditory information attainment for children in different types of educational placements especially in regular school.

After surgery of cochlear implants, long term of language and speech rehabilitation is necessary, otherwise, cochlear implant is meaningless, will only inevitably become a risk investment. Listening ability is also need to be tested periodically as well as some others involving speech, language and the development of aural skills, regularly check cochlear performance etc. Familycentered early intervention plays an irreplaceable important role, meanwhile, parents are faced with a series of problems to be solved listed as group characteristics of children with cochlear implants tend towards diversification; a growing number of children with cochlear implants choose regular school; a decreasing number of deaf school students and; the lack of specialized teacher in regular schools.

\section{Family-centered early intervention}

In daily life, children depend on parents for everything, including diet, sleep, games and so on. After cochlear implantation surgery, the whole family requires a great deal of professional and technical support. Parents should intensively observe children and focus on the following aspects:

Check whether children's response frequency to sound stimulus decrease; Check whether sound and speech is abnormal; Check whether children physically discomfort; Check cochlear device regularly;

Some universal positive changes in behavior:

Audio and visual attention increase; Rapid detection of sound; More sound involving games appear; Reduce the dependence of sign language or gestures; Voice frequency matching the sign language and gestures increases.

Study (Wu, 2014) indicates that several main influencing factors including age of cochlear implants surgery, multiple disabilities, cochlear using time and family factors involving family financial situation, parents' educational level. Ability of independent implement guiding rehabilitation, integrating all sources of early intervention etc. is affected directly by their educational level. Parents 
actively participate in early intervention after the surgery of cochlear implants, which is the key factor improving ideal language development of children. Family function (Wang et al., 2011) works effectively depends on several main aspects: the knowledge of hearing impairment and cochlear implants; the cope strategies of the family facing of challenges; the mutual support between family members; the environment of raising children; the communication between children and family members; the social communication of children beyond the family; the ability of the family to independent solving problems; the ability of the family to make a decision and; the family expectation for children.

Family-centered early intervention emphasizes strong relationship among children, parents and the family. Children are unique in each family, only deeply understand the whole of family culture, values, family structure, even the daily life can meet the needs of the children. Relationship between parents and children even their common experiences also influence early intervention. Style of interaction and quality between them reflects their common experiences and knowledge, which is also the carrier of early intervention. For the family, strength and resource of every family member are united to meet the needs of the whole family. Support network is formed among family members, providing the best language learning environment and keep a warm and nurturing environment.

Statistics show that about $95 \%$ of children with hearing impairment are born in the family with hearing parents. Those hearing parents generally do not have sign language skills, communication barriers with children exist commonly. At the beginning of cochlear implants surgery, it is difficult to predict that how well develop of the language, in that case, it is important to give priority to oral communication, and supplement by sign language. In the newborn period, communication between adults and children is mainly based on the effective communication mode that has already built by the interaction between themselves. Such mode positively impacts the language development of children. Researches of the past ten years (Preisler \& Tvingstedtand, 2008) clearly demonstrated that sign language is beneficial for children in communication, language learning, social-emotional and cognitive development. However, it is easy to be ignored by parents or even rejected curtly.

Children mainly learn from and imitate the communication between themselves and parents. Main care-givers provide a vivid auditory learning environment to stimulate the production of dialogue. It is also an effective way to identify the extent of the voice recognition. If children cannot recognize mostly, which implies that more visual input, namely sign language or gestures are necessary. In bilingual environment, if children can identify most language, it will be a good choice to treat sign language as the second language. When 
some children decide to communicate only in sign language, professional sign language teachers could build good examples for them.

Due to the lack of knowledge about how does hearing impairment influence the development of language, some parents often control the interaction between them and the children, but such kind of way is extremely disadvantageous for the development of children. On the contrary, interaction model associated with children's intention which focuses on the content of the dialogue with children instead of dull linguistic form to promote speech and language acquisition. Establishing comprehensive hearing system to promote self-monitoring of speech and response actively to the environment, comply with natural sequential patterns of hearing, perception, speech, and cognitive stimulation. Children with hearing impairment do not understand words, sentences or be unable to use, mutual interaction with peers will be limited. Further, amount of vocabulary and sentences is very important for subsequent development of reading and writing skills.

\section{Early intervention team building}

After cochlear implantation surgery, the cochlear implants center provides long term postoperation technical supports. Traditionally, clinical effects are tested by speech perception, speech generation and language ability. For children who do not have multiple disabilities, three main factors to predict their performance related with listening which including dominating oral communication both at home and in school, rich effective auditory learning environment and parents' knowledge of cochlear implants. Other influencing factors involve with cochlear implants continuous using time and auditory rehabilitation (Wang et al., 2011).

Early intervention completely link with the daily life of children, based on natural situation such as dieting time, games, dressing etc. Early intervention team should implement parents consulting, provide a rich language environment, strengthen daily communication frequency, and promote children to listen and to speak. Early implantation and early family intervention raises the possibility of children reach the universal language development level till 5 years old (Moog \& Geers, 2010), which also improve language expression, listening and reading skills, and social emotion.

Speech and language therapist provide technical supports for the development of listening, communication and cognitive skills, in the form of individual or group intervention. Intervention should be focused on the communication and transition for preschool education. Furthermore, it is important to offer educational placement information for parents, through which parents may recognize that environment in regular school, is beneficial for 
children to practice listening and speaking. Educational placement should be decided according to the individual characteristics of children rather than the ideal irrational choice of the parents. Social networking of parents is also a part of the intervention team, which is a stage for parents to share and communicate their personal experiences with each other. In a word, all kinds of services are provided to create appropriate environment for children.

Early intervention team building, psychological consultants are included. It is a long way that from the diagnosis to cochlear implants, parents felt anxious, sad, angry, even despairing at the beginning of diagnosis, they struggled with whether implant cochlear, once they had cochlear implants, subsequently, they doubted about the listening development of children and their future. All of such factors could damage the family functions. Psychological consultants could help family members in psychological, finding appropriate coping strategies to solve problems.

Multidisciplinary team may include social workers, daily care center staff and nursing staff in hospital. Teachers for children with hearing impairment face new challenges in implement of family centered intervention. In the past, they only focused on educating the children, but now they should also provide family consultation and supports, and even visit family regularly and guide parents solve most problems properly. In general, early intervention team should be sensitive and clear of children's individual characteristics, intension of intervention, and prior items of early intervention. For those families with situations of bad financial status, damaged family structure, or incomplete family function, early intervention team should especially pay attention to.

\section{Reform of deaf school}

The fate of children with hearing impairment over the past half century has experienced a great change, from electronic hearing aids to extensive hearing screening and early cochlear implantation. On one hand, cochlear implants is a good opportunity for children with hearing impairment to listen to the world, on another hand, most children with cochlear implants can speak and communicate orally, they tend to be educated in regular school. More students with cochlear implants study in regular school, and fewer students study in deaf school, those changes pose challenges for teachers both from regular and deaf school. Some deaf education scholars propose that in the 21st century, deaf school should reform to meet the needs of students.

To meet the needs of children with special needs, at least one special school should be built in every county in the mainland of China. In the background of inclusive education, many special schools set up resource centers to offer individual educational support for students with special needs but study 
in regular schools. In special school, professional special education teachers educate students with different special needs, such as students with autistic spectrum disorder, with mental retardation, with cerebral palsy, and so on. Even though there are resource center, teachers are busy in educating in special school. As for the students with cochlear implants and hearing aids who study in regular school, they do not get enough appropriate attention or technical support. In addition, around 30 to 40 percent of students with hearing impairment, they may also have learning disorders, autistic spectrum disorder, or serious behavioral disorders, attention deficit hyperactive disorders etc. usually they are educated in special school with limited individual support.

There are fewer deaf schools than special schools, partially deaf schools should reform, change the only educational function into comprehensive functional service center, which includes early intervention, child-care center, preschool education, primary school education, secondary vocational education, inclusive education center, hearing test and rehabilitation. Comprehensive functional service center provides support for both regular and special schools. Comprehensive service center could offer technical support and recommend educational placement transition for students with hearing impairment. Regular school and resource center in special school serve students with hearing impairment after their transition. Once some difficult problems appear but they cannot sole, they could transit students to comprehensive service center or consult them directly. As a result, special school resource center, regular school and comprehensive service center, those three constitute a coherent dynamic system, professional team guidance cover all.

Reform of the deaf school challenges the staff, which is also a challenge for the teachers in regular school. Despite of family consultation and information support, periodical on-the-job training is also necessary which including cochlear implants simple troubleshooting, regularly inspection of the hearing aids to meet timely needs of students in school. The teacher may consider study situation of students from five aspects: attention, communication, class participation, behaviors and academic achievement, to discover and solve possible problems. Whatever educational placement, effective listening environment is very important for students with cochlear implants. Imagine that even hearing children would be interfered in a noisy environment. Noise and reverberation influence the speech recognition of children with cochlear implants. Some recommendations are listed here such as equipped with FM radio system, electromagnetic induction coil to improve the sound quality and help children with hearing impairment receive acoustic signal.

In order to provide appropriate education, suitable courses are also needed. As far as possible to carry out group teaching and multidisciplinary (Leo et al., 
2012) team support, to meet the needs of students, adaptation of school courses may include:

Introduction of cochlear implants to the students. Help students get to know the cochlear implants and some simple hearing equipment debugging;

Oral language input. After the cochlear implantation surgery, children are be able to listen to the world, listening practice is necessary, especially in the early years after surgery, daily speech and language therapy is very important;

Reading practice. Reading practice should be particularly focused on some vocabulary and syntax which are used with high frequency;

Additionally, students with cochlear implants in regular school, they feel lonely, which intensify the possibility that the social-emotional problem, regular school should consider place children with cochlear implants in the same school or class. Actively rich and colorful activities could be carried out, such as organizations for children with cochlear implants, weekend study groups, summer camps and so on. During activities, children and their parents both have opportunities to freely share experiences.

\section{Conclusion}

On one hand, children with hearing impairment have more educational choices when cochlear implants bring them hearing ability. Group characteristics of children with hearing impairment tend to be diversified because of hearing aids and cochlear implants. On another hand, more and more children with cochlear implants choose to study in regular schools, this new situation pose challenges for teachers in both deaf schools and regular schools. In regular schools, professional special education teachers obviously are insufficient. On the contrary, fewer students are educated in deaf school.

To provide the least restrictive educational environment, school reform is imperative. To meet the needs of students, teachers' specified knowledge should be strengthened.

Regular school teachers have great concern with children with cochlear implants, such kind of unnecessary worry comes from they do not know well about what is hearing impairment or cochlear implants. Additionally, parents usually underestimated the demands of special needs once they hold high expectation for the development of children after cochlear implants surgery either despite of intensive postoperative rehabilitation.

More and more children accept cochlear implants surgery in earlier ages, to focus on the assessment and monitoring of hearing, speech and language, cognitive and social emotional development. Especially, the early intervention team building and cooperation of multidisciplinary are really important. 
This study was partly research results of project „School adaptation of children with hearing impairment in regular class". Project No. 15SB0020 Sichuan Normal University

\section{References}

Anneke, V., \& Leo, R. et al. (2012). Changing Realities in the Classroom for Hearing Impaired Children with Cochlear Implant. Deafness \& Education International, 14 (1), 36-47.

Jones, L. R., \& Agrawal, S. et al. (2010). Effect of Age at Onset of Deafness on Binaural Sensitivity in Electric Hearing in Humans. Journal of acoustical society America, 127, 1, 400-414.

Leo, R., \& Johan, B. et al. (2012). Changing Schools for the Deaf: Updating the Educational Setting for Our Deaf Children in the $21^{\text {st }}$ Century, A Big Challenge. Deafness \& Education International, 14 (1), 48-59.

Liu, J. J, \& Sun, X. B. (2012). Review of Reheabilitation of Children with Cochlear Implants. Disability Research, 2, 11.

Liu, S. L. (2009). New Trends in Deaf Education Development in Westeran Countries. Chinese Journal of Special Education, 1, 46.

Moog, J. S., \& Geers, A. E. (2010). Early Educational Placement and Later Language Outcomes for Children with Cochlear Implants. Otology \& Neurotology, 31, 1315-1319.

Peters, R., \& Wyss, J. et al. (2010). Worldwide Trends in Bilateral Cochlear Implantation. The laryngoscope 120, May, 18.

Preisler, G., \& Tvingstedtand, M. (2008). A Psychosocial Follow-up Study of Deaf Preschool Children Using Cochlear Implants. Child: Care,Health \& Development, 28 (5), 403418.

Sparreboom, M., \& Schoonhoven, V. J. et al. (2010). The Effectiveness of Bilateral Cochlear Implants for a Profound Deafness in Children: A Systematic Review. Otology \& Neurology, 31, 1062-1071.

Verhaert, N., \& Willems, J. et al. (2008). Impact of early hearing screening on language development and education level: evaluation of 6 years of university hearing screening in Flanders-Belgium. International journal of pediatric otorhinolaryngology, 72, 599608.

Wang, N., \& Liu, C. J. et al. (2011). Predictor of Auditory Performance in Mandarin Chinese Children with Cochlear Implants. Otology \& Neurotology, 32, 937-942.

Wu, J. J. (2014). Children with Cochlear Implants Educational Placement and School Adjustment. E-pedagogium, IV, 79-85.

Noam, Y., \& Naama, T. et al. (2011). Demographic Factors Influencing Educational Placement of the Hearing Impaired Child with a Cochlear Implant. Otology \& Neurology, 32, 943-947. 